\title{
Determination of Catechin and Epicatechin Content in Chocolates by High-Performance Liquid Chromatography
}

\author{
Raju V. S. S. Gottumukkala, Nareshraju Nadimpalli, \\ Kannababu Sukala, and Gottumukkala V. Subbaraju \\ Natsol Laboratories Private Limited, 2nd Floor, Research \& Development Building, Ramky Commercial Hub, \\ Jawaharlal Nehru Pharma City, Visakhapatnam 531 019, India
}

Correspondence should be addressed to Gottumukkala V. Subbaraju; subbarajugv@gmail.com

Received 11 May 2014; Revised 8 August 2014; Accepted 8 August 2014; Published 29 October 2014

Academic Editor: Isabel C. F. R. Ferreira

Copyright (C) 2014 Raju V. S. S. Gottumukkala et al. This is an open access article distributed under the Creative Commons Attribution License, which permits unrestricted use, distribution, and reproduction in any medium, provided the original work is properly cited.

\begin{abstract}
A simple and sensitive reversed phase high-performance liquid chromatographic (HPLC) method has been developed for the determination of catechin and epicatechin in cocoa powder and chocolates. The separation was achieved on a reversed phase $\mathrm{C} 18$ column (TARGA) $5 \mu \mathrm{m}$ by gradient elution with a flow rate of $1.0 \mathrm{~mL} / \mathrm{minute}$ with an operating temperature of $30^{\circ} \mathrm{C}$ and detection with a UV-Visible detector was at $280 \mathrm{~nm}$. The method was validated for linearity, precision, intra- and interday precision, and accuracy. The developed method is successfully applied for the determination of catechin and epicatechin content in chocolates. The Godiva brand chocolate contains high concentration of epicatechin.
\end{abstract}

\section{Introduction}

Dietary polyphenols comprise a wide range of aromatic compounds. The polyphenols that are present in foods can be divided broadly into two main groups: flavonoids and other compounds that are mostly monocyclic aromatic acids. Flavonoids contain two phenolic moieties and a pyran unit [1]. Catechin (1) and epicatechin (2) belong to flavonoids.

Cocoa and chocolate products have the highest concentration of flavonoids among commonly consumed foods and also have many health promoting properties. Over 10 percent of the weight of cocoa powder is flavonoids. Cocoa and chocolate are among the most concentrated sources of the procyanidin flavonoids, catechin, and epicatechin. For example, dark chocolate has been found to be very nutritious, potent antioxidant, that improves blood flow, lowers blood pressure, raises HDL, protects LDL against oxidation, lowers the risk of cardiovascular disease, protects the skin against the sun, and improves blood flow to the brain.

The active ingredient of dark chocolate has been identified as epicatechin [2]. Epicatechin has proved that consumption of plain, dark chocolate resulted in an increase in both the total antioxidant capacity and the (-) epicatechin content of blood plasma but that these effects are markedly reduced when the chocolate is consumed with milk or if milk is incorporated as milk chocolate. A study conducted over a two-week period in 21 healthy adult subjects with a daily consumption of high-flavonoid (213 mg procyanidins, $46 \mathrm{mg}$ epicatechin) or low-flavonoid dark chocolate bars ( $46 \mathrm{~g}, 1.6 \mathrm{oz}$ ) observed improvement in endothelial function associated with an increase in plasma epicatechin concentrations and no changes in oxidative stress measures, lipid profiles, blood pressure, body weight or BMI were observed. Epicatechin has also been proved to improve vascular functions and insulin sensitivity, to reduce blood pressure and platelet reactivity, and to be good antioxidant [3-7].

The growing interest in these compounds and the number of methods for quantification in various herbs, herbal extracts, herbal formulations, and food items have been developed. A thorough literature search revealed that the high-performance liquid chromatographic (HPLC) methods are more predominant. Several HPLC methods with different detection modes, ultraviolet [8-13], photodiode array [14, 15], electrochemical $[10,16,17]$, capillary electrophoresis $[18,19]$, 
fluorescence $[10,20]$, and mass $[21,22]$ detection, as well as few high-performance thin layer chromatographic (HPTLC) methods [23, 24], are also reported.

In view of the growing interest in epicatechin, we report a simple, rapid, and precise gradient HPLC method with an economical mobile phase for the simultaneous separation and quantification of catechin and epicatechin, in cocoa powder and chocolates. The present paper describes the method of determination of catechin and epicatechin.

\section{Materials and Methods}

2.1. Commercial Samples. Commercial chocolates were procured from USA and from local market.

2.2. Reagents and Chemicals. All HPLC grade solvents (acetonitrile, methanol, water, and orthophosphoric acid) were purchased from Qualigens (Mumbai, India). Standard catechin and epicatechins were prepared by Natsol Laboratories Private Limited, Visakhapatnam, India. Identity and purity (>98\%) of the compounds were confirmed by chromatographic (HPLC) and spectral (IR, Mass, and NMR) data.

2.3. HPLC Instrumentation and Conditions. The HPLC system (Shimadzu, $2010 \mathrm{CHT}$ ) consisted of quaternary pump with vacuum degasser, thermostatted column compartment, autosampler, and UV detector. A reverse-phase column (TARGA, C18, $5 \mu, 250 \times 4.6 \mathrm{~mm}$ ) was used and the column temperature was maintained at $30^{\circ} \mathrm{C}$. HPLC mobile phase was prepared as follows. Solution A: $0.1 \mathrm{~mL}$ of orthophosphoric acid dissolved in $900 \mathrm{~mL}$ of HPLC grade water and the volume was made up to $1000 \mathrm{~mL}$ with water and the solution was filtered through $0.45 \mu \mathrm{m}$ membrane filter and degassed in a sonicator for 3 minutes, Solution B: acetonitrile. Mobile phase was run using gradient elution: at the time 0.01 minutes $11 \% \mathrm{~B}$; at the time 30 minutes $25 \% \mathrm{~B}$; at the time 35 to 39 minutes $100 \% \mathrm{~B}$; and at the time 40 to 50 minutes $11 \% \mathrm{~B}$. The mobile phase flow rate was $1.0 \mathrm{~mL} /$ minute and the injection volume was $10 \mu \mathrm{L}$. The eluents were detected and analyzed at $280 \mathrm{~nm}$.

2.4. Preparation of Standard Solutions. Stock solutions of catechin and epicatechin $(4 \mathrm{mg} / \mathrm{mL})$ were prepared by dissolving standards into methanol. Less concentrated solutions were prepared, as needed by dilution with methanol.

\subsection{Preparation of Samples}

2.5.1. Cocoa Powder. $50 \mathrm{mg}$ of the sample was transferred into a $100 \mathrm{~mL}$ volumetric flask containing $75 \mathrm{~mL}$ of methanol, sonicated for 10 minutes, diluted to $100 \mathrm{~mL}$ with methanol, and filtered through $0.45 \mu \mathrm{m}$ membrane filter.

2.5.2. Chocolates. About $10 \mathrm{gm}$ of chocolate sample was extracted with methanol on a hot water bath till the colorless methanolic extract was obtained. Combine all the methanolic fractions and filter using Whatman no. 1 filter paper. Evaporate the combined filtered extract to $100 \mathrm{~mL}$ on a roto
TABLE 1: Specificity.

\begin{tabular}{lcc}
\hline Compound & $\begin{array}{c}\text { Retention time } \\
\text { (minutes) standard }\end{array}$ & $\begin{array}{c}\text { Retention time (minutes) } \\
\text { Godiva Chocolatier 85\% } \\
\text { cacao }\end{array}$ \\
\hline Catechin & $16.264 \pm 0.2$ & $16.383 \pm 0.2$ \\
Epicatechin & $19.304 \pm 0.2$ & $19.476 \pm 0.2$ \\
\hline
\end{tabular}

evaporator. Filter this solution through $0.45 \mu \mathrm{m}$ membrane filter.

2.6. Calibration. Calibration standards were prepared by diluting the catechin and epicatechin stock solutions with methanol in the concentration range of $100-600 \mu \mathrm{g} / \mathrm{mL}$. The standard curves were obtained by using the peak areas of six different concentrations in six replicate assays and were expressed by the linear least square regression equation.

2.7. Method Validation. The specificity of the method was ascertained by analyzing the standards and the samples. The peaks for catechin and epicatechin in the samples were confirmed by comparing the retention times of the peak with those of standards.

The linearity of the method was checked with catechin and epicatechin standards with the calibration curves in the range $100-600 \mu \mathrm{g} / \mathrm{mL}$, using six different concentrations in six replicate assays. Limit of detection (LOD) and limit of quantification (LOQ) were obtained from the standard deviation $(\sigma)$ of the blank response $(n=6)$ and slope $(S)$ of the calibration curve using the formulae $3.3 \sigma / S$ and $10 \sigma / S$, respectively.

Accuracy was determined by spiking preanalyzed sample with low, medium, and high concentrations in the calibration range of the standard catechin and epicatechin and analyzed by the proposed method. The experiments were conducted six times to check the recovery of the analyte at different levels in the samples.

Precision is a measure of repeatability of the analytical method in the normal operating conditions. Precision (intraand interday) of the method was verified by six determinations of three concentrations of the standard catechin and epicatechin on the same day (intraday) and on different days (interday) which were carried out and expressed as percent relative standard deviation (\%RSD).

\section{Results and Discussion}

3.1. Optimization of Chromatographic Conditions. A simple method was developed for the determination of catechin and epicatechin based on a reversed phase HPLC separation combined with ultraviolet detection. The gradient system was chosen to minimize the variations of the baseline, considering the simplicity, precision, and accuracy. The stability of the samples and standards of catechin and epicatechin were checked and found to be stable for 12 hours.

A systematic study conducted on the effect of column selection and mobile phase composition on the separation of 


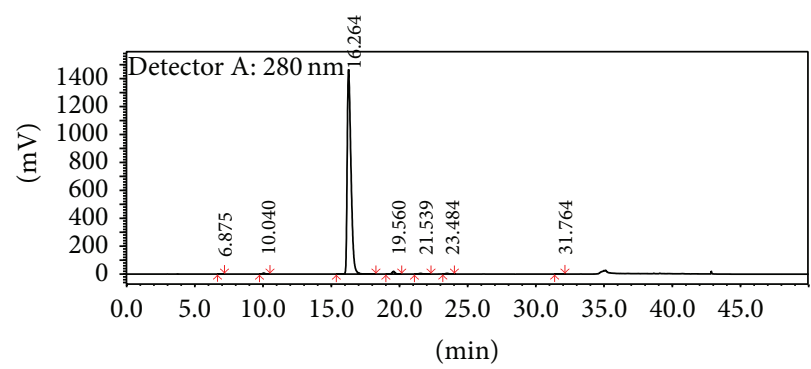

(a)

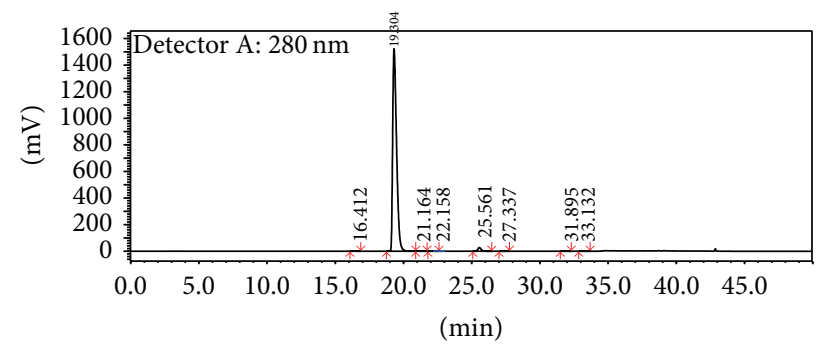

(b)

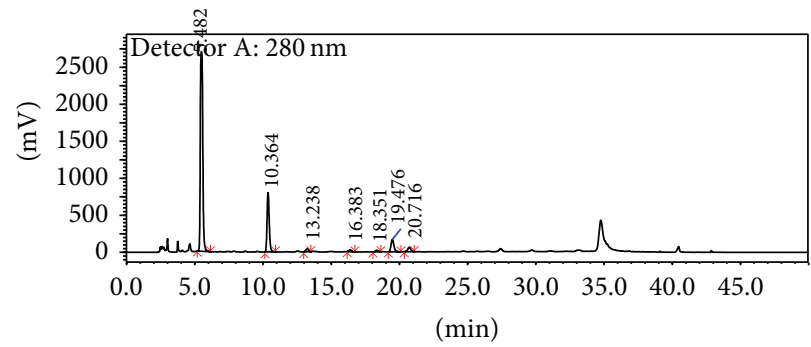

(c)

Figure 1: HPLC chromatograms. (a) Standard catechin $(400 \mu \mathrm{g} / \mathrm{mL})$. (b) Standard epicatechin (400 $\mu \mathrm{g} / \mathrm{mL})$. (c) Godiva Chocolatier $85 \%$ cacao.

TABLE 2: Calibration, linearity, and LOD and LOQ data.

\begin{tabular}{lccccc}
\hline Compound & Linearity range $(\mu \mathrm{g} / \mathrm{mL})$ & Regression equation & Correlation coefficient & LOD $(\mu \mathrm{g} / \mathrm{mL})$ & $\mathrm{LOQ}(\mu \mathrm{g} / \mathrm{mL})$ \\
\hline Catechin & $100-600$ & $y=74777 x+13899$ & 0.9990 & 0.012 & 0.15 \\
Epicatechin & $100-600$ & $y=77598 x-17409$ & 0.9980 & 0.036 & 0.45 \\
\hline
\end{tabular}

$y=$ peak area; $x=$ concentration of analyte.

TABLE 3: Recovery studies $(n=6)$.

\begin{tabular}{lccc}
\hline Compound & $\begin{array}{c}\text { Amount of } \\
\text { compound } \\
\text { added }(\mu \mathrm{g})\end{array}$ & $\begin{array}{c}\text { Amount of } \\
\text { compound } \\
\text { recovered } \\
(\mu \mathrm{g} \pm \text { S.D. })\end{array}$ & \% recovery \\
\hline \multirow{3}{*}{ Catechin } & 200 & $200.48 \pm 1.25$ & 100.24 \\
& 400 & $399.52 \pm 0.96$ & 99.88 \\
Epicatechin & 600 & $600.51 \pm 1.09$ & 100.08 \\
& 200 & $198.95 \pm 1.30$ & 99.48 \\
& 600 & $401.05 \pm 1.05$ & 100.26 \\
& 600 & $599.85 \pm 1.35$ & 99.98 \\
\hline
\end{tabular}

catechin and epicatechin based on the resolution and peak shapes. Best results were obtained with TARGA C18 column, with $5 \mu \mathrm{m}$ particle size, $250 \mathrm{~mm}$ length, and $4.6 \mathrm{~mm}$ i.d, and a gradient system of mobile phase comprises $0.1 \%(\mathrm{v} / \mathrm{v})$.

Phosphoric acid in water (Mobile phase A) and acetonitrile (Mobile phase B) with $1.0 \mathrm{~mL} /$ minute flow rate enable the baseline separation of catechin and epicatechin within 50 minutes. All the separations were performed at $30^{\circ} \mathrm{C}$, absorption measurement at $280 \mathrm{~nm}$ was selected, and the compounds catechin and epicatechin were effectively detected (Figure 1).
3.2. Validation of the Assay Method. Method for quantitative analysis of catechin and epicatechin was validated with regard to its specificity, linearity, accuracy, and precision by utilizing the ICH guidelines [25]. The specificity of the method was confirmed by reliability of compound peaks corresponding to catechin and epicatechin in the sample. The sample was spiked with standard catechin and epicatechin, individually, which were separated by gradient mobile phase system. The peak areas of the catechin and epicatechin in the sample were changed consistently with their corresponding standards. The study confirmed the stable retention times of catechin and epicatechin in the samples which were comparable to retention times of standards with \pm 0.2 to \pm 0.3 minutes of variation (Table 1).

The linearity of the method was checked with standards corresponding to catechin and epicatechin with the calibration curves in the concentration range $100-600 \mu \mathrm{g} / \mathrm{mL}$. The regression equation and the correlation coefficient were observed with six replicate analyses for each concentration. The results of linearity data were reported in (Table 2) showing that the correlation coefficient of the equation was $>0.99$ and the two calibration curves yielded straight lines in a wide range.

The limit of detection (LOD) of catechin and epicatechin was $0.012 \mu \mathrm{g} / \mathrm{mL}$ and $0.15 \mu \mathrm{g} / \mathrm{mL}$, respectively, and the limit 
TABLE 4: Intra- and interday precision $(n=6)$.

\begin{tabular}{|c|c|c|c|c|c|c|}
\hline \multirow{2}{*}{ Compound } & \multicolumn{3}{|c|}{ Intraday } & \multicolumn{3}{|c|}{ Interday } \\
\hline & Concentration $(\mu \mathrm{g} / \mathrm{mL})$ & Average peak area & $\%$ RSD & Concentration $(\mu \mathrm{g} / \mathrm{mL})$ & Average peak area & $\%$ RSD \\
\hline \multirow{3}{*}{ Catechin } & 200 & 1507937 & 0.13 & 200 & 1537115 & 0.20 \\
\hline & 400 & 2924044 & 0.27 & 400 & 2968715 & 0.23 \\
\hline & 600 & 4458083 & 0.33 & 600 & 4444284 & 0.67 \\
\hline \multirow{3}{*}{ Epicatechin } & 200 & 1633896 & 0.03 & 200 & 1609962 & 0.08 \\
\hline & 400 & 3065181 & 0.04 & 400 & 3079683 & 0.21 \\
\hline & 600 & 4699541 & 0.21 & 600 & 4617629 & 0.06 \\
\hline
\end{tabular}

TABLE 5: Determination of catechin and epicatechin in samples ( $n=6 \% \%$ relative standard deviations are given in parenthesis).

\begin{tabular}{|c|c|c|c|}
\hline Sample & & Catechin & Epicatechin \\
\hline Cocoa powder ${ }^{1}$ & & $0.20 \%(0.72)$ & $0.28 \%(0.55)$ \\
\hline Chocolates & Serving size $(\mathrm{gm})$ & Catechin per serving size & Epicatechin per serving size \\
\hline Lindt Excellence, $90 \%$ cocoa $^{2}$ & 40 & $6.04 \mathrm{mg}(0.27)$ & $17.32 \mathrm{mg}(0.17)$ \\
\hline Lindt Excellence, $85 \%$ cocoa $^{2}$ & 40 & $4.80 \mathrm{mg}(0.38)$ & $22.76 \mathrm{mg}(0.57)$ \\
\hline Lindt Excellence, $70 \%$ cocoa $^{2}$ & 40 & $7.84 \mathrm{mg}(0.32)$ & $28.56 \mathrm{mg}(0.24)$ \\
\hline Ghirardelli Chocolate, $86 \% \mathrm{cacao}^{3}$ & 45 & $4.50 \mathrm{mg}(0.51)$ & $23.85 \mathrm{mg}(0.28)$ \\
\hline Ghirardelli Chocolate, $72 \%$ cacao $^{3}$ & 38 & $5.78 \mathrm{mg}(0.34)$ & $27.70 \mathrm{mg}(0.33)$ \\
\hline Ghirardelli Chocolate, $60 \% \mathrm{cacao}^{3}$ & 38 & $4.79 \mathrm{mg}(0.32)$ & $17.78 \mathrm{mg}(0.23)$ \\
\hline Godiva Chocolatier, $85 \%$ cacao $^{4}$ & 40 & $5.20 \mathrm{mg}(0.79)$ & $31.68 \mathrm{mg}(0.08)$ \\
\hline Safeway Select chocolate, $85 \%$ cacao $^{5}$ & 40 & $4.76 \mathrm{mg}(0.83)$ & $10.52 \mathrm{mg}(1.04)$ \\
\hline Safeway Select chocolate, $72 \%$ cacao $^{5}$ & 40 & $4.84 \mathrm{mg}(0.86)$ & $14.64 \mathrm{mg}(0.69)$ \\
\hline Green \& Black's chocolate, $50 \%$ cocoa $^{6}$ & 40 & $3.28 \mathrm{mg}(0.36)$ & $11.92 \mathrm{mg}(0.14)$ \\
\hline Bournville Cranberry chocolate, $50 \%$ cocoa $^{7}$ & 33 & $1.49 \mathrm{mg}(1.25)$ & $3.76 \mathrm{mg}(0.18)$ \\
\hline Bournville Rich Cocoa chocolate, $50 \% \operatorname{cocoa}^{7}$ & 33 & $1.09 \mathrm{mg}(0.27)$ & $3.60 \mathrm{mg}(1.81)$ \\
\hline
\end{tabular}

${ }^{1}$ Samples were supplied by M/S Natsol Laboratories Private Limited, Visakhapatnam, India.

${ }^{2}$ Lindt and Sprungli Inc., Stratham, NH 03885, USA.

${ }^{3}$ Ghirardelli Chocolate Company, San Leandro, CA 94578, USA.

${ }^{4}$ Godiva Chocolatier company, USA, product of Germany.

${ }^{5}$ Safeway Select Inc., P.O. Box 99, Pleasanton, CA 94566, USA, product of Switzerland.

${ }^{6}$ Green \& Black's, Parsippany, NJ 07054, USA, made in Italy.

${ }^{7}$ Cadbury India Limited, Mumbai, India.

of quantification (LOQ) of the catechin and epicatechin was $0.036 \mu \mathrm{g} / \mathrm{mL}$ and $0.45 \mu \mathrm{g} / \mathrm{mL}$, respectively.

Accuracy of the analytical method was determined by spiking sample with known amounts of catechin and epicatechin at three concentration levels. The samples were analyzed under optimized conditions and the recovery rates were observed in the range $99.98 \%$ to $100.24 \%$ for catechin and $99.48 \%$ to $100.26 \%$ for epicatechin (Table 3 ). The average recovery percentage values were found to be $100.06 \%$ and 99.91\% for catechin and epicatechin.

The precision of the method was validated both for intra- and interday variation. The results depicted in (Table 4) showed that no significant intra- and interday variations were observed in the analysis of catechin and epicatechin.

3.3. Application of the Method. The method developed was applied to analyze cocoa powder and ten different chocolates which were procured from domestic market and United
States of America. The results presented in (Table 5) reveal that epicatechin is present in higher concentrations than catechin in the cocoa powder and chocolates. The presence of excipients like sugar, milk fat, and vanilla does not interfere in the determination of catechin and epicatechin in chocolates.

\section{Conclusions}

The growing importance of epicatechin as a constituent of therapeutic significance necessitated the development of highly sensitive and selective methods. A simple reversed phase HPLC method has been developed and the results demonstrate that the method developed was highly specific, accurate, and precise and it could be used in the determination of catechin and epicatechin content in chocolates. Interestingly, the branded chocolates contain higher levels of catechin and epicatechin. Chocolates of Indian origin contain lesser content of catechin and epicatechin comparable to the brands available in USA. 


\section{Conflict of Interests}

All the members are currently working for Natsol Laboratories Private Limited, Visakhapatnam, India.

\section{Acknowledgments}

The authors thank the management of M/S Natsol Laboratories Private Limited, Visakhapatnam, India, for encouragement.

\section{References}

[1] H. S. Lee and B. W. Widmer, "Phenolic compounds," in Hand Book of Food Analysis, L. M. L. Nollet, Ed., pp. 821-894, Marcel Dekker, New York, NY, USA, 1999.

[2] M. Panneerselvam, Y. M. Tsutsumi, J. A. Bonds et al., "Dark chocolate receptors: epicatechin-induced cardiac protection is dependent on $\delta$-opioid receptor stimulation," American Journal of Physiology: Heart and Circulatory Physiology, vol. 299, no. 5, pp. H1604-H1609, 2010.

[3] M. B. Engler and M. M. Engler, "The emerging role of flavonoidrich cocoa and chocolate in cardiovascular health and disease," Nutrition Reviews, vol. 64, no. 3, pp. 109-118, 2006.

[4] E. Ramiro-Puig and M. Castell, "Cocoa: antioxidant and immunomodulator," British Journal of Nutrition, vol. 101, no. 7, pp. 931-940, 2009.

[5] Y. Steffen, T. Schewe, and H. Sies, "Myeloperoxidase-mediated LDL oxidation and endothelial cell toxicity of oxidized LDL: Attenuation by (-)-epicatechin," Free Radical Research, vol. 40, no. 10, pp. 1076-1085, 2006.

[6] V. Bayard, F. Chamorro, J. Motta, and N. K. Hollenberg, "Does flavanol intake influence mortality from nitric oxide-dependent processes? Ischemic heart disease, stroke, diabetes mellitus, and cancer in Panama," International Journal of Medical Sciences, vol. 4, no. 1, pp. 53-58, 2007.

[7] H. Schroeter, C. Heiss, J. Balzer et al., “(-)-Epicatechin mediates beneficial effects of flavanol-rich cocoa on vascular function in humans," Proceedings of the National Academy of Sciences of the United States of America, vol. 103, no. 4, pp. 1024-1029, 2006.

[8] S. T. Saito, A. Welzel, E. S. Suyenaga, and F. Bueno, "A method for fast determination of epigallocatechin gallate (EGCG), epicatechin (EC), catechin (C) and caffeine (CAF) in green tea using HPLC," Ciencia e Tecnologia de Alimentos, vol. 26, no. 2, pp. 394-400, 2006.

[9] M. Jain, V. Ravichandran, P. K. Jain, and R. K. Agrawal, "HPLC method for estimation of (-)-epicatechin in pterocarpus marsupium herbal extracts and pharmaceutical dosage formulations," Eurasian Journal of Analytical Chemistry, vol. 6, no. 1, pp. 31-39, 2011.

[10] J. L. Donovan, D. L. Luthria, P. Stremple, and A. L. Waterhouse, "Analysis of (+)-catechin, (-)-epicatechin and their 3'- and 4'-Omethylated analogs. A comparison of sensitive methods," Journal of Chromatography B: Biomedical Sciences and Applications, vol. 726, no. 1-2, pp. 277-283, 1999.

[11] T. Lakshmi, A. Magesh, and R. Rajendran, "Estimation of biomarker epicatechin in ethanolic bark extract of Acacia catechu willd by HPLC method," Journal of Pharmaceutical Sciences and Research, vol. 4, no. 3, pp. 1764-1767, 2012.

[12] P. R. Machonis, M. A. Jones, B. T. Schaneberg, and C. L. KwikUribe, "Method for the determination of catechin and epicatechin enantiomers in cocoa-based ingredients and products by high-performance Liquid chromatography: single-laboratory validation," Journal of AOAC International, vol. 95, no. 2, pp. 500-507, 2012.

[13] M. C. Roman, J. Hildreth, and S. Bannister, "Determination of catechins and caffeine in Camellia sinensis, raw materials, extracts, and dietary supplements by HPLC-UV: single Laboratory validation," Journal of AOAC International, vol. 96, no. 5, pp. 933-941, 2013.

[14] Y. Zu, C. Li, Y. Fu, and C. Zhao, "Simultaneous determination of catechin, rutin, quercetin kaempferol and isorhamnetin in the extract of sea buckthorn (Hippophae rhamnoides) leaves by RPHPLC with DAD," Journal of Pharmaceutical and Biomedical Analysis, vol. 41, no. 3, pp. 714-719, 2006.

[15] N. Dubey, N. Dubey, R. Mehta, and A. Saluja, "A selective high performance liquid chromatographic method for estimation of catechin in ayurvedic taila preparations," Asian Journal of Research in Chemistry, vol. 2, no. 1, pp. 66-69, 2009.

[16] T. Unno, Y. M. Sagesaka, and T. Kakuda, "Analysis of tea catechins in human plasma by high-performance liquid chromatography with solid-phase extraction," Journal of Agricultural and Food Chemistry, vol. 53, no. 26, pp. 9885-9889, 2005.

[17] H. Shintani, "Determination of Flavonoids (catechins) by HPLC ECD," Pharmaceutica Analytica Acta, vol. 4, no. 5, pp. 238-239, 2013.

[18] M. Kofink, M. Papagiannopoulos, and R. Galensa, “(-)-catechin in cocoa and chocolate: occurence and analysis of an atypical flavan-3-ol enantiomer," Molecules, vol. 12, no. 7, pp. 1274-1288, 2007.

[19] M. Piovezan, D. García-Seco, G. A. Micke, J. Gutiérrez-Mañero, and B. Ramos-Solano, "Method development for determination of (+)-catechin and (-)-epicatechin by micellar electrokinetic chromatography: annual characterization of field grown blackberries," Electrophoresis, vol. 34, no. 15, pp. 2251-2258, 2013.

[20] L. Shumow and A. Bodor, "An industry consensus study on an HPLC fluorescence method for the determination of $( \pm)$ catechin and ( \pm )-epicatechin in cocoa and chocolate products," Chemistry Central Journal, vol. 5, no. 1, article 39, 2011.

[21] W. Chang, L. Qiu, H. Guo, and et al, "LC MS/MS for simultaneous determination of four major active catechins of tea polyphenols in rat plasma and its application to pharmacokinetics," Chinese Herbal Medicines, vol. 2, no. 4, pp. 289-296, 2010.

[22] D. Shen, Q. Wu, M. Wang, Y. Yang, E. J. Lavoie, and J. E. Simon, "Determination of the predominant catechins in Acacia catechu by liquid chromatography/electrospray ionization-mass spectrometry," Journal of Agricultural and Food Chemistry, vol. 54, no. 9, pp. 3219-3224, 2006.

[23] Y. Jaiswal, P. Tatke, S. Gabhe, and A. Vaidya, "Rapid high performance thin layer chromatographic method for quantitation of catechin from extracts of cashew leaves-a short report," Polish Journal of Food and Nutrition Sciences, vol. 63, no. 1, pp. 49-54, 2013.

[24] V. Glavnik, B. Simonovska, and I. Vovk, "Comparison of TLC and HPLC methods used for analysis of (-)-epicatechin and its dimer procyanidin B2 in chocolate," Journal of Planar Chromatography, vol. 23, no. 3, pp. 230-232, 2010.

[25] ICH Topic Q2 (R1), Validation of Analytical Procedures: Text and Methodology, 2005. 

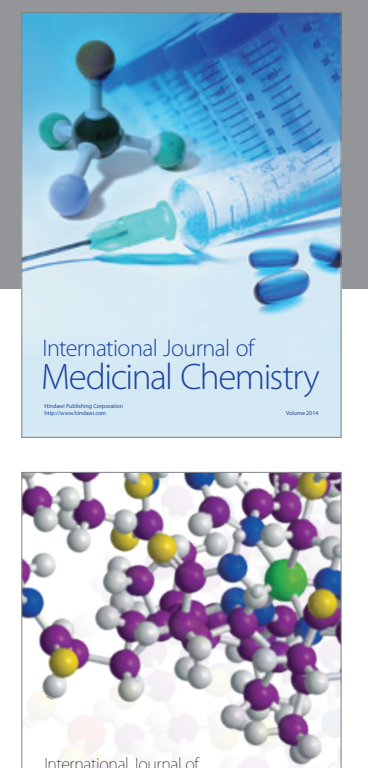

\section{Carbohydrate} Chemistry

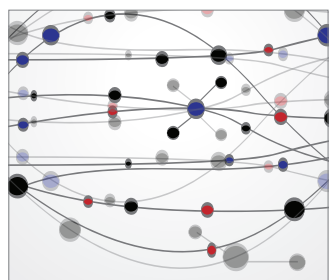

The Scientific World Journal
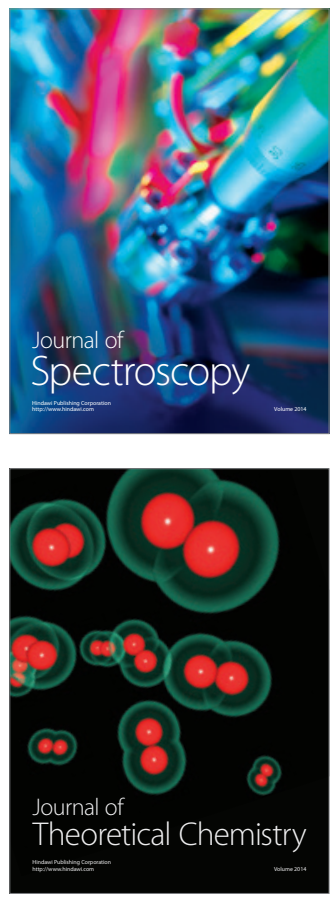
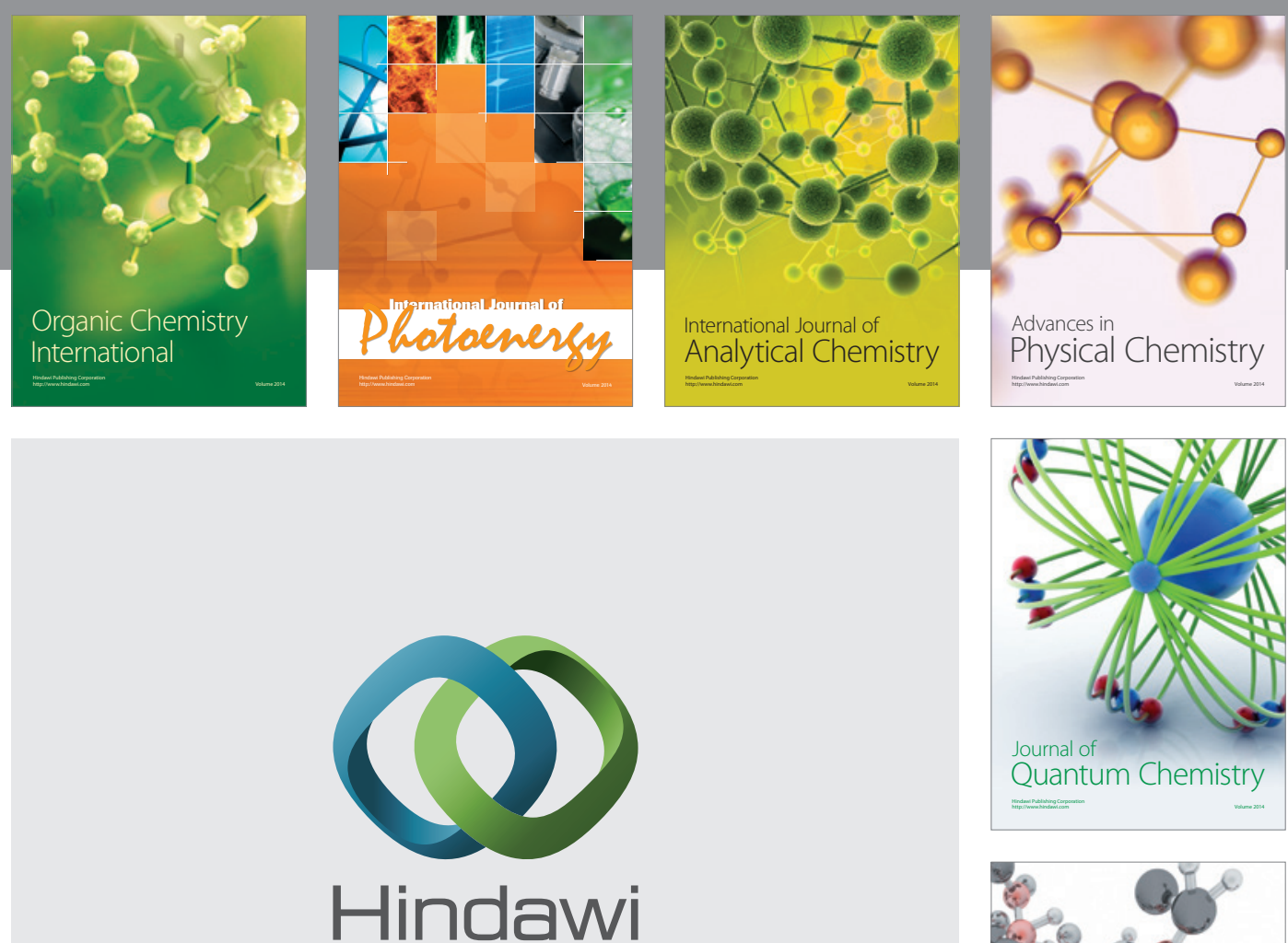

Submit your manuscripts at

http://www.hindawi.com

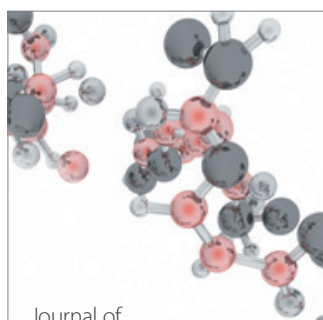

Analytical Methods

in Chemistry

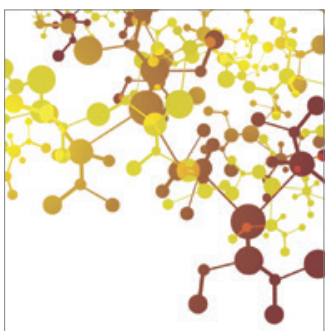

Journal of

Applied Chemistry

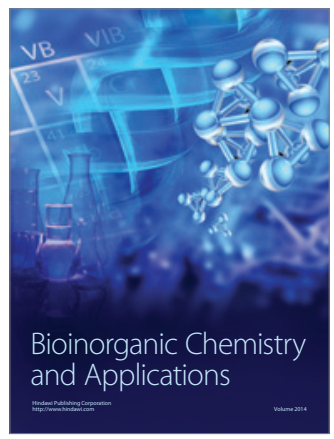

Inorganic Chemistry
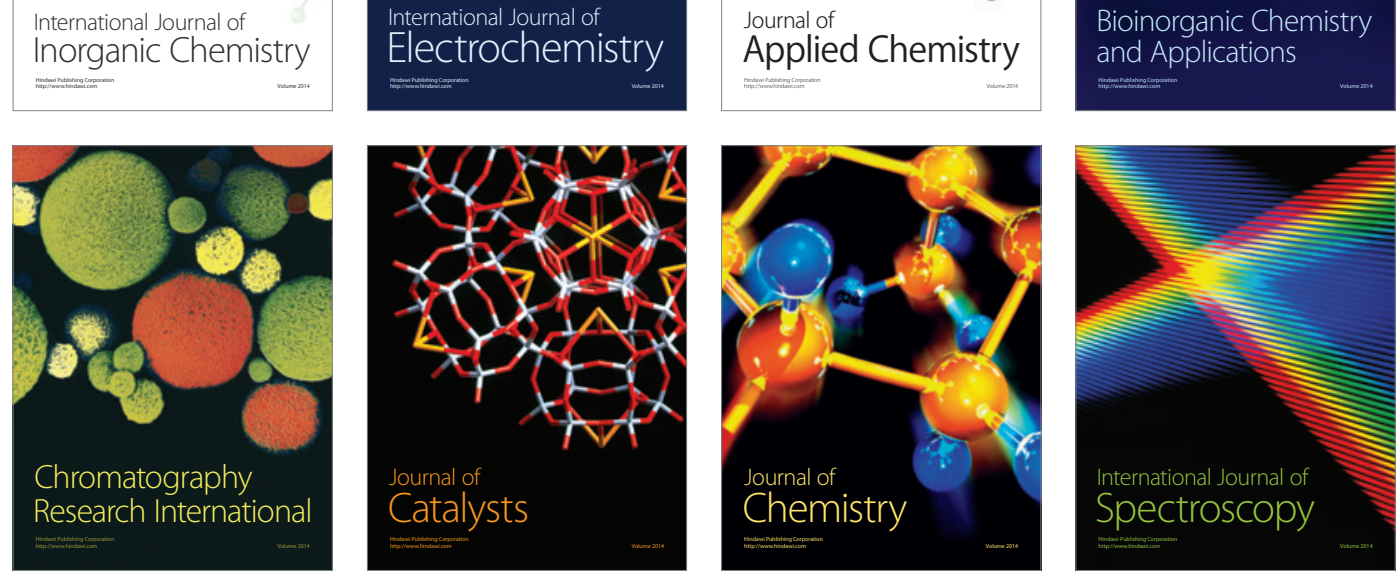